\title{
Suscetibilidade de Biótipos de ARRoz-vermelho e de Cultivares DE ARROZ IRRIGADO AO HERBICIDA IMAZETHAPYR ${ }^{1}$
}

\author{
Susceptibility of Red Rice Biotypes and Commercial Rice Cultivars to Imazethapyr
}

\author{
DORNELLES, S.H.B. ${ }^{2}$, GARCIA, D.C. ${ }^{3}$, LORETO, E.L. ${ }^{4}$, CANTO-DOROW, T.S. ${ }^{5}$, MANFRON, P.A. ${ }^{6}$, \\ SANCHOTENE, D.M. ${ }^{7}$ e OLIVEIRA, L.F.V. ${ }^{8}$
}

\begin{abstract}
RESUMO - Para avaliar a suscetibilidade de biótipos de arroz-vermelho(Oryza sativa) e cultivares comerciais de arroz ao herbicida imazethapyr, realizou-se um ensaio em casa de vegetação com cinco biótipos de arroz-vermelho (acessos Santa Maria 5, Pelotas 3, Rio Pardo 1, Manoel Viana 2 e Catuçaba 1), dois cultivares comerciais de arroz: Clearfield® (IRGA 422 CL e Puitá INTA CL) e um cultivar convencional (IRGA 417). Utilizou-se a metodologia de curvas de dose-resposta proposta por Seefeldt et al. (1995). A metodologia de curvas de resposta foi gerada a partir dos parâmetros do modelo logístico e dos valores de $\mathrm{I}_{50}$. Os biótipos de arrozvermelho e os cultivares foram submetidos a seis doses do herbicida imazethapyr $(0 ; 33,12$; 66,$25 ; 132,5 ; 265,0 ;$ e 530,0 g i.a. ha ${ }^{-1}$ ). As plantas de arroz foram contadas e coletadas no $20^{\circ}$ dia após a aplicação dos tratamentos. A análise do percentual de dano foi realizada através de avaliação visual da fitointoxicação (\%), massa verde e massa seca das plantas. Analisando as curvas e os resultados da análise da variância, pode-se inferir que os cultivares Clearfield Irga 422 CL e Puitá INTA CL foram significativamente iguais ao biótipo de arroz-vermelho Catuçaba 1, resistindo a doses de imazethapyr superiores à recomendada em campo para o sistema Clearfield $\mathbb{R}$. Os biótipos Manoel Viana 2, Santa Maria 5 e Pelotas 3 agruparam-se com o cultivar convencional IRGA 417, sendo suscetiveis à dose comercial do herbicida. O biótipo Rio Pardo 1 também é resistente ao herbicida imazethapyr, porém menos resistente que o biótipo Catuçaba 1.
\end{abstract}

Palavras-chave: Clearfield, controle, Oryza sativa, planta daninhas, resistência

\begin{abstract}
To evaluate the susceptibility of biotypes of red rice (Oryza sativa) and commercial rice cultivars to the herbicide imazethapyr, a greenhouse assay was conducted with five red rice biotypes (accesses Santa Maria 5, Pelotas 3, Rio Pardo 1, 2 and Manoel Viana Catuçaba 1), two commercial rice cultivars: Clearfield ${ }^{\circledR}$ (Irga CL 422 and CL Puit INTA), and a conventional cultivar (Irga 417). The methodology of dose-response curves proposed by Seefeldt et al. (1995) was applied. The methodology of response curves was generated from the parameters of the logistic model and the values of $I_{50}$. The red rice biotypes and cultivars were subjected to six doses of the herbicide imazethapyr $\left(0,33.12,66.25,132.5,265.0\right.$ and 530.0 $\mathrm{g}$ a.i. ha $\left.\mathrm{a}^{-1}\right)$. Rice plants were counted and collected on the 2Oth day after treatment application. Damage percentage analysis was performed by visual assessment of phytotoxicity (\%), plant green mass, and plant dry mass. Through the curves and results of the analysis of variance, it could be inferred that the cultivars Irga Clearfield CL 422 and CL Puit INTA were significantly equal to red rice biotype Catuçaba 1, resisting to imazethapyr doses higher than those recommended to the Match Clearfield ${ }^{\circledR}$ system in the field. Biotypes Manoel Viana 2, Santa Maria 5, and Pelotas 3 grouped with the conventional cultivar IRGA 417, and were susceptible to the commercial dose of the herbicide. Rio Pardo 1 biotype is also resistant to the herbicide imazethapyr, but less than biotype Catuçaba 1.
\end{abstract}

Keywords: Cleardeald, control, Oryza sativa, weed, resistance.

Recebido para publicação em 21.12.2009 e na forma revisada em 17.12.2010

2 Professor Adjunto, Dep. de Biologia, Universidade Federal de Santa Maria - UFSM, <sylvio@smail.ufsm.br>; ${ }^{3}$ Professor Associado, Dep. de Fitotecnia, UFSM; ${ }^{4}$ Professor Associado, Dep. de Biologia, UFSM; ${ }^{5}$ Professora Associada, Dep. de Biologia, UFSM; ${ }^{6}$ Professor Titular, Dep. de Fitotecnia, UFSM; ${ }^{7}$ Doutorando em Agronomia, UFSM; ${ }^{8}$ Mestrando em Genética, Universidade Federal do Rio Grande do Sul - UFRGS.

Planta Daninha, Viçosa-MG, v. 28, p. 1097-1106, 2010. Número Especial 


\section{INTRODUÇÃO}

O Rio Grande do Sul é o principal produtor de arroz irrigado; $60 \%$ de todo o arroz produzido no Brasil é colhido de lavouras do Rio Grande do Sul e Santa Catarina. Nos últimos anos a produtividade da cultura tem evoluído, em função de novas tecnologias que são empregadas pelos rizicultores, como a tecnologia Clearfield ${ }^{\circledR}$ (Noldin et al., 2004; Schwanke et al., 2008). Contudo, ainda não foi atingido o patamar ideal de produtividade de 10 toneladas por hectare (Menezes et al., 2008), em razão de diversos fatores, como manejo de água, manejo de fertilidade, qualidade de sementes, sistematização de várzeas e controle fitossanitário (Agostinetto, 2001).

Um dos fatores que interferem nesse processo é a presença de plantas daninhas nas várzeas arrozeiras, principalmente as gramíneas. Dentre as espécies que causam danos à cultura do arroz, destaca-se o arroz-vermelho (Oryza sativa), citado como principal entrave à elevação do rendimento de arroz em $80 \%$ dos municipios produtores do Rio Grande do Sul (Marchezan, 1994). O arroz-vermelho é do mesmo gênero e espécie do arroz cultivado (Oryza sativa) e, segundo Fleck et al. (2008), ocupa posição geneticamente intermediária entre esta espécie e seus ancestrais Oryza rufipogon e Oryza glumaepatula. Em razão disso, torna-se dificil seu controle por meio de herbicidas graminicidas, uma vez que um dano por fitointoxicação no arroz-vermelho também reflete-se em danos consideráveis no cultivar convencional (não resistente a herbicida). Nesse contexto, através da obtenção de cultivares de arroz resistentes a herbicidas do grupo químico das imidazolinonas, por indução à mutação (arroz mutado AHAS-resistente) foi possivel utilizar uma tecnologia química para controle de gramíneas, sobretudo o arrozvermelho, com cultivares seletivos a determinadas doses do herbicida imazethapyr (Croughan, 1996). Esse sistema foi patenteado pela empresa BASF e denominado Clearfield $\mathbb{R}$. No Brasil encontram-se registrados no sistema Clearfield $\mathbb{}{ }^{\circledR}$ os cultivares de arroz irrigado IRGA 422 CL, Tuno CL, Sator CL, Puitá INTA CL e SCS Epagri 115 (AGROFIT, 2008). A dose de registro para IRGA $422 \mathrm{CL}$ do herbicida Only (imazethapyr $75 \mathrm{~g} \mathrm{~L}^{-1}+$ imazapic $25 \mathrm{~g} \mathrm{~L}^{-1}$ ) é de 1,0 litro por hectare do produto comercial para aplicação em pós-emergência das plantas daninhas e da cultura quando estas encontram-se com duas a três folhas abertas (AGROFIT, 2008). Este cultivar está sendo semeado no Rio Grande do Sul desde a safra 2002/2003. Em função da atual dificuldade de controle de todo o complexo arroz-vermelho infestante, entre biótipos de arroz-vermelho ocorrentes nas várzeas do Rio Grande do Sul (Dornelles et al., 2004; Noldin et al., 2004; Moraes et al. 2009) foi introduzido recentemente o cultivar Puitá INTA CL, desenvolvido na Argentina. Este cultivar resiste a doses duas a três vezes superiores à dose praticada em sistema em que se utiliza o cultivar IRGA $422 \mathrm{CL}$. Este programa, que inclui o cultivar Puitá INTA CL, visa dar maior possibilidade de controle dos biótipos de arrozvermelho resistentes à dose de $1,0 \mathrm{~L} \mathrm{ha}^{-1}$ do herbicida imazethapyr.

Entretanto, ocorrem no Rio Grande do Sul biótipos de arroz-vermelho que resistem a doses até três vezes superiores à dose de registro do herbicida Only $\left(1,0 \mathrm{~L} \mathrm{ha}^{-1}\right)$, conforme relatado por Dornelles et al. (2004), podendo colocar o sistema Clearfield em dificuldade, uma vez que, segundo Kuk et al. (2008), a pressão de seleção pelo uso contínuo e intensivo do herbicida imazethapyr pode levar ao aparecimento de biótipos de arroz-vermelho resistentes ao herbicida, o que torna o sistema ambientalmente insustentável. Essa pressão de seleção, aliada à fuga (escape) de genes de resistência do cultivar AHAS-resistente para os biótipos de arroz-vermelho, foi verificada por pesquisadores como Rajguru et al. (2005), confirmando que a introgressão desses genes de resistência no arroz-vermelho resulta em plantas resistentes aos herbicidas imidazolinonas, sobretudo ao imazethapyr. Nesse contexto, nos arrozais de diversos países que utilizam a tecnologia que alia cultivares mutados AHAS-resistente à possibilidade de utilização de determinadas doses do herbicida imazethapyr, ocorrem biótipos de arrozvermelho suscetiveis ao herbicida (enzima ALS sensivel), naturalmente tolerantes ao herbicida (por modificações no local de ação da enzima ALS) e aqueles com introgressão de genes de resistência (Avila et al., 2005; Rajguru et al., 2005; Kuk et al., 2008), o que torna dificil o controle da planta daninha nas doses convencionais do herbicida. 
Em função do quadro atual, de ocorrência no Rio Grande do Sul de biótipos de arrozvermelho suscetiveis, menos resistentes e mais resistentes ao herbicida imazethapyr nas várzeas do Estado, e das possiveis diferenças de tolerância/resistência desses biótipos ao herbicida imazethapyr, o objetivo deste trabalho foi avaliar a suscetibilidade de biótipos de arroz-vermelho do Estado a doses crescentes do herbicida imazethapyr, por meio da metodologia de curva dose-resposta proposta por Seefeldt et al. (1995).

\section{MATERIAL E MÉTODOS}

O experimento foi conduzido em casa de vegetação da Universidade Federal de Santa Maria, durante o ano agrícola de 2008, utilizando vasos de polietileno de 1,4 L de capacidade, em delineamento experimental de blocos ao acaso em esquema fatorial $8 \times 6$, com quatro repetições. Os tratamentos do fator A consistiram da combinação de dois cultivares Clearfield $\mathbb{R}$ tolerantes ao herbicida imazethapyr (IRGA 422 CL e Puitá INTA CL), um cultivar convencional suscetivel ao herbicida imazethapyr (IRGA 417) e cinco biótipos de arroz-vermelho do Estado do Rio Grande do Sul com suspeita de tolerância ou resistência ao herbicida imazethapyr (acessos Pelotas 3, Santa Maria 5, Manoel Viana 2, Rio Pardo 1 e Catuçaba 1); e os do fator B, por doses crescentes de imazethapyr $(0 ; 33,12 ; 66,25 ; 132,5$; 265,0; e 530,0 gramas de ingrediente ativo de imazethapyr por hectare).

A semeadura nos vasos ocorreu no dia 22 de novembro de 2008, em uma profundidade de $1 \mathrm{~cm}$. A aplicação dos tratamentos herbicidas, em pós-emergência das plantas, ocorreu no dia 5 de dezembro de 2008, quando as plantas emergidas dos cultivares e do arrozvermelho encontravam-se com duas a três folhas. Utilizou-se equipamento costal pressurizado $\mathrm{aCO}_{2}$, regulado para um volume de calda aplicado de $150 \mathrm{~L} \mathrm{ha}^{-1}$. As condições climáticas no momento da aplicação eram: temperatura média de $23,5{ }^{\circ} \mathrm{C}$ e umidade relativa média do ar de $60,8 \%$, medidas com equipamento Kestre1 3000. As avaliações consistiram de análises visuais de fitointoxicação, no sétimo e no vigésimo dia após a aplicação dos tratamentos herbicidas. O efeito dos herbicidas sobre as plantas foi determinado pelo método qualitativo, caracterizado por avaliações visuais com base em escalas arbitrárias estabelecidas em escala percentual de zero (nenhuma injúria sobre as plantas) a 100\% (morte de todas as plantas) (Frans et al., 1986). Ao final do vigésimo dia, realizou-se a contagem do número de plantas por vaso e a coleta das plantas para determinação da massa verde das plantas (MV) e, após secagem em estufa a $60{ }^{\circ} \mathrm{C}$, da massa seca (MS) de plantas. Nesse sentido, para obtenção das curvas de doseresposta, foram utilizados os resultados de fitointoxicação $\left(\mathrm{FITO}_{50}\right)$, massa verde $\left(\mathrm{MV}_{50}\right)$ e massa seca $\left(\mathrm{MS}_{50}\right)$ aos 20 dias após a aplicação, quando já eram visualizadas as injúrias provocadas pelos tratamentos, nas plantas de arroz IRGA 422 CL e Puitá INTA CL. Os dados obtidos foram testados quanto ao atendimento às pressuposições do modelo e submetidos à análise da variância (ANOVA), para verificação das interações entre os fatores. As médias entre cultivares e biótipos foram comparadas para massa seca pelo teste da diferença mínima significativa (DMS) a $1 \%$ de probabilidade.

$$
Y=C+\left(\frac{D-C}{1+e^{\left[b\left(\log (x)-\log \left(X_{50}\right)\right)\right]}}\right)
$$

Quanto às interações significativas, os dados foram ajustados ao modelo de regressão não linear do tipo log-logístico, usando-se o modelo proposto por Seefeldt et al. (1995), em que $\mathrm{D}$ representa o limite superior; $\mathrm{C}$, o limite inferior, sendo a resposta média nas doses mais elevadas; e o parâmetro b descreve a inclinação da curva em torno do $\mathrm{I}_{50}$. Os parâmetros exigidos na equação foram obtidos através da plotagem dos dados de fitointoxicação (\%) da redução em porcentagem da massa verde (MV) e massa seca (MS) de plantas em relação à testemunha. Os gráficos foram obtidos a partir de uma matriz básica de dados, analisada no programa SigmaPlot ${ }^{\circledR}$ versão 11 . Os valores de $\mathrm{FITO}_{50}, \mathrm{MV}_{50}$ e $\mathrm{MS}_{50}$ caracterizam os niveis de suscetibilidade das populações de plantas daninhas ao herbicida (Moreira et al., 2007). Com os valores de FITO $_{50}$ e $\mathrm{MS}_{50}$ obtém-se o fator de resistência (FR) para cada combinação das populações com suspeita de resistência e a população suscetível. O fator 
de resistência é o resultado do quociente entre a $\mathrm{FITO}_{50}$ do biótipo resistente e a FITO $_{50}$ do biótipo suscetível $\left(\mathrm{FR}=\mathrm{FITO}_{50} \mathrm{R} / \mathrm{Fito}_{50} \mathrm{~S}\right)$. O fator de resistência (FR) expressa o número de vezes em que a dose necessária para controlar a população resistente (R) é superior à dose que controla $50 \%$ da população suscetivel (S).

O DNA foi extraído de tecido foliar congelado, utilizando o protocolo descrito por Oliveira et al. (2009). Para as PCRs (Polymerase Chain Reaction), foi usada uma aliquota de DNA de trabalho, no qual o DNA genômico obtido na extração foi diluído em 1:10 de $\mathrm{H}_{2} \mathrm{O}$ ultrapura (MILLI-Q).

$\mathrm{Na}$ amplificação e análise dos microssatélites, foram utilizados cinco lócus de microssatélites: RM154 descrito por Akagi et al. (1996), RM204 e RM212 descrito por Chen et al. (1997), RM422 e RM545 descrito por Temnykh et al. (2001).

A amplificação e análise do gene acetolactato sintase (ALS) foram utilizados representantes dos principais agrupamentos formados nas análises de inferência filogenia e estrutura populacional, com base nos dados de microssatélites. Assim, os acessos nessa análise foram: Catuçaba 1, Guaíba 2, Santo Antonio da Patrulha 1. Também foram utilizados os cultivares IRGA 417 e IRGA $422 \mathrm{CL}$ (Figura 3), conforme metodologia descrita e aplicada por Dornelles (2009).

\section{RESULTADOS E DISCUSSÃO}

As Figuras 1 e 2 e as Tabelas 1 e 2, para os resultados de $\mathrm{MV}_{50}$ e $\mathrm{MS}_{50}$, indicam que os biótipos Santa Maria 5, Manoel Viana 2 e Pelotas 3 apresentaram maior redução percentual de massa verde (MV) e massa seca (MS) que os biótipos Catuçaba 1 e Rio Pardo 1, sendo estatisticamente iguais ao percentual de redução desses parâmetros medidos para o cultivar suscetivel IRGA 417. Verifica-se, também, que o biótipo Catuçaba 1 apresentou redução percentual de MV e MS, em valores absolutos, inferior àquela obtida com o cultivar IRGA $422 \mathrm{CL}$ e próxima daquela obtida com o cultivar Puitá INTA CL. Em termos de dose do herbicida imazethapyr, os resultados experimentais demonstram que os biótipos suscetíveis Santa Maria 5, Manoel Viana 2 e Pelotas
3 têm $50 \%$ da MV e da MS reduzida com doses inferiores a $1,0 \mathrm{~L} \mathrm{ha}^{-1}$ (dose comercial do herbicida imazethapyr), enquanto o biótipo Catuçaba 1 terá $50 \%$ de sua MV reduzida com a dose de 2,2 $\mathrm{L} \mathrm{ha}^{-1}$ (dobro da dose utilizada em campo para cultivos com IRGA $422 \mathrm{CL}$ ) e $50 \%$ da MS com dose de 1,8 L.ha $^{-1}$. O biótipo Rio Pardo 1 tolera doses de até $1,2 \mathrm{~L} \mathrm{ha}^{1}$ do herbicida imazethapyr, configurando-se como um biótipo com suscetibilidade intermediária entre os biótipos suscetiveis Santa Maria 5, Manoel Viana 2 e Pelotas 3, em relação ao biótipo resistente Catuçaba 1.

Esses resultados demonstram que, para parcela dos biótipos de arroz-vermelho ocorrentes em áreas de cultivo de arroz irrigado do Rio Grande do Sul, o herbicida imazethapyr ainda pode proporcionar controle eficiente na dose de 1,0 $\mathrm{L} \mathrm{ha}^{-1}$. Entretanto, para biótipos como Rio Pardo 1 e Catuçaba 1, são necessárias doses superiores à dose de controle para os biótipos suscetíveis. No caso de Catuçaba 1, esse grau de resistência acontece para doses superiores às praticadas no sistema de cultivo que utiliza o cultivar Puitá INTA CL (cultivar mutado para o gene AHAS); esse resultado sugere que o gene AHAS encontrado no biótipo Catuçaba 1 (Figura 3) foi oriundo de hibridações entre os cultivares Clearfield e o arroz-vermelho existentes na área. Isso torna o sistema Clearfield-arroz vulnerável, uma vez que a pressão de seleção pelo uso continuado e sistemático das áreas e do herbicida imazethapyr permitirá selecionar biótipos com maior grau de tolerância ou resistência ao herbicida (Kuk et al., 2008), o que é ambiental e economicamente problemático em função do uso de doses maiores e progressivas do herbicida na tentativa de controlar a planta daninha, acumulando maior quantidade de resíduos do herbicida no solo das várzeas ou nos mananciais de água adjacentes, causando assim problemas para as culturas subsequentes e ao meio ambiente.

Os resultados encontrados neste trabalho corroboram os obtidos por Avila et al. (2005), os quais, nas condições de produção de arroz nos EUA, encontraram nas populações de arrozvermelho biótipos suscetiveis, biótipos moderadamente tolerantes, biótipos tolerantes e biótipos resistentes ao herbicida imazethapyr para a dose empregada no sistema Clearfield. 


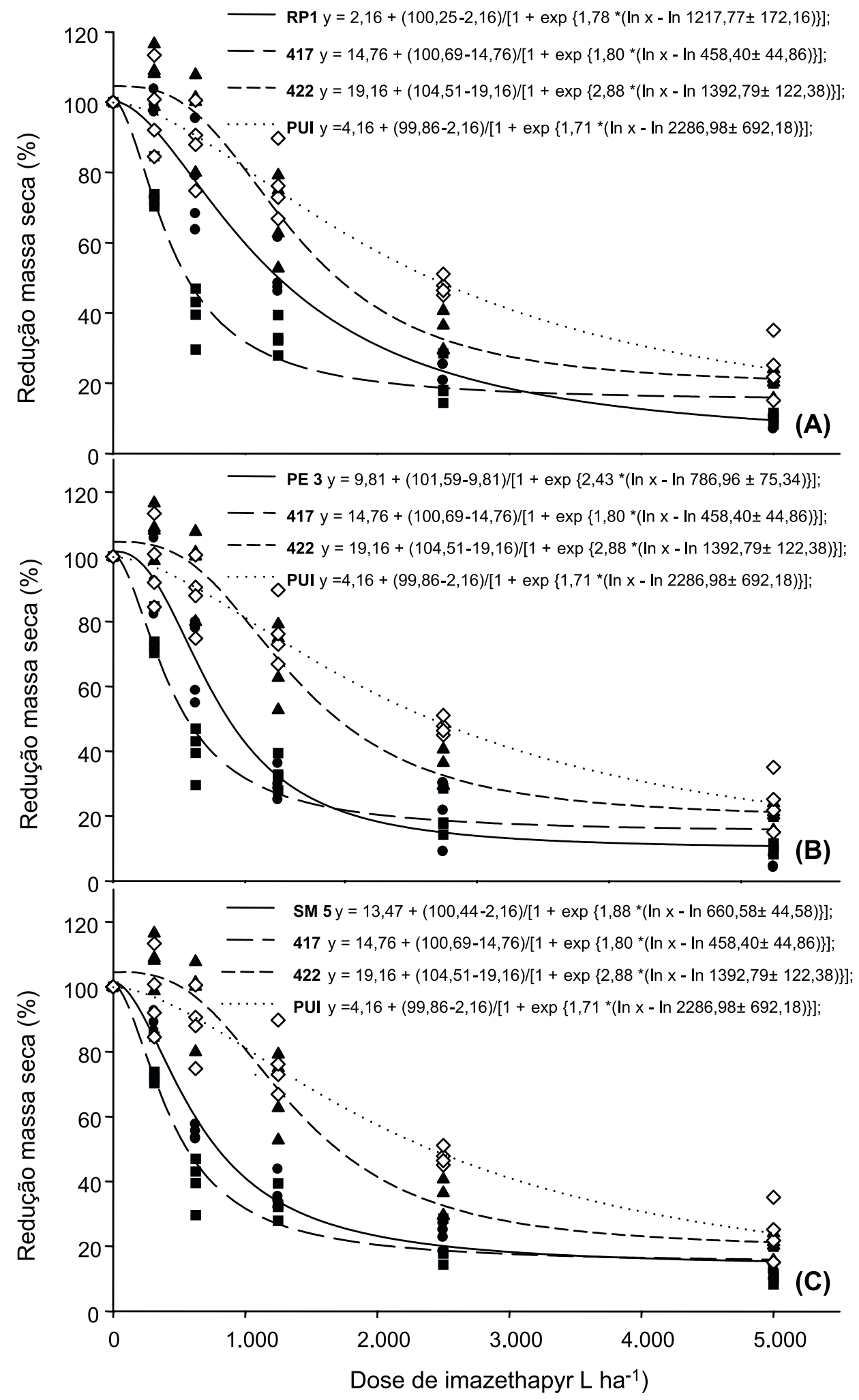

Figura 1 - Percentual de redução de massa seca dos biótipos Rio Pardo 1 (RP1), Pelotas 3 (PE3) e Santa Maria 5 (SM5) em relação aos cultivares IRGA 422 CL, Puitá CL INTA e IRGA 417, em função de doses crescentes do herbicida imazethapyr - Santa Maria-RS, 2009. 
Esses resultados também foram encontrados nas condições do Rio Grande do Sul, onde os biótipos Manoel Viana 2, Santa Maria 5 e Pelotas 3 são suscetiveis ao herbicida imazethapyr na dose comercial $\left(1,0 \mathrm{~L} \mathrm{ha}^{-1}\right)$, o biótipo Rio Pardo 1 é pouco resistente ao herbicida nesta dose e o biótipo Catuçaba 1 é resistente. Esta resposta para Catuçaba 1 era esperada, visto que, em análise de DNA realizada por sequenciamento (Figura 3 ), o

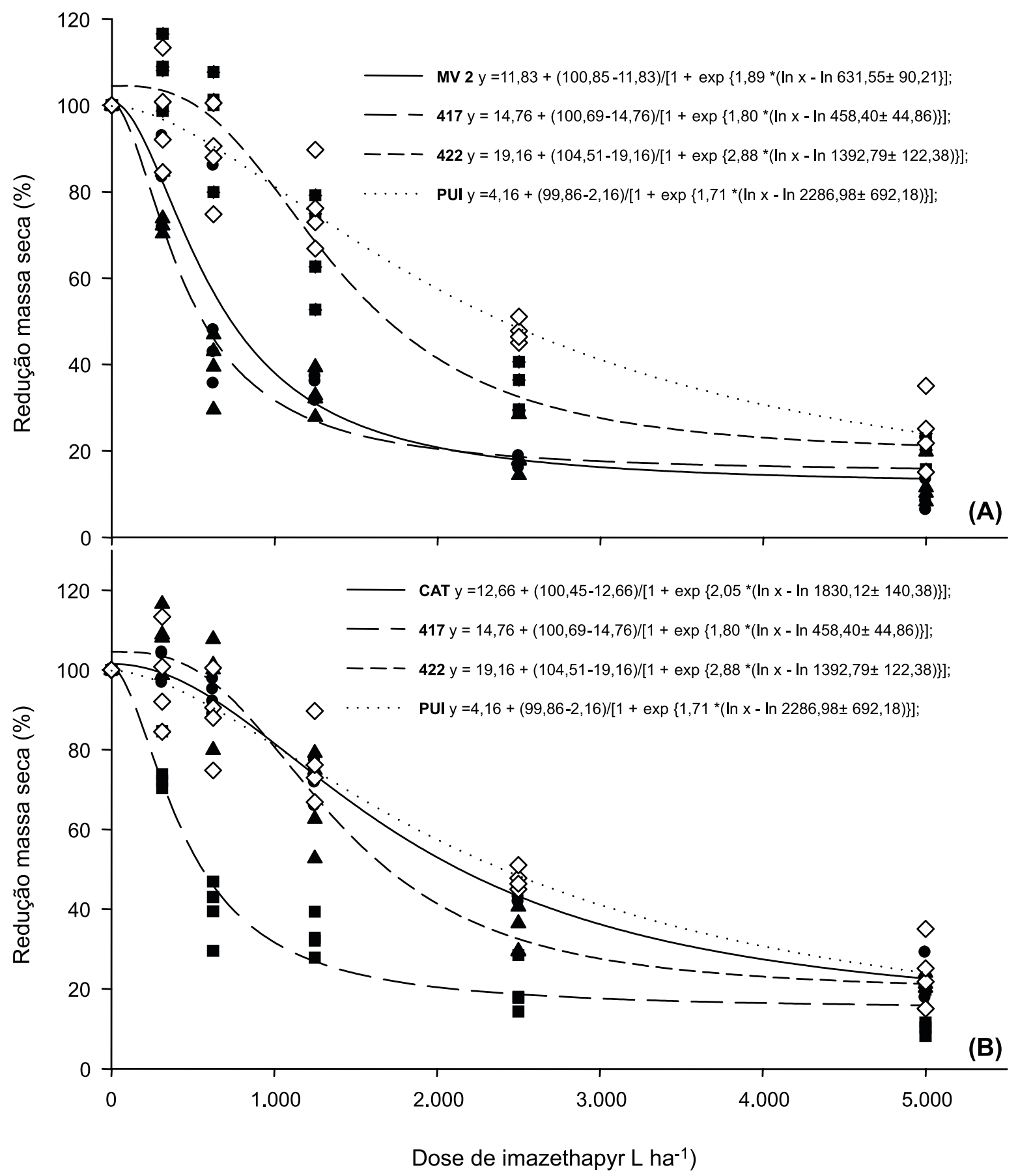

Figura 2 - Percentual de redução de massa seca dos biótipos Manoel Viana 2 (MV2) e Catuçaba 1 (CAT1) em relação aos cultivares IRGA 422 CL, Puitá CL INTA e IRGA 417, em função de doses crescentes do herbicida imazethapyr - Santa Maria-RS, 2009. 
Tabela 1 - Dose de imazethapyr em g i.a. ha ${ }^{-1}$ que causa 50\% de fitotoxicidade ( $\left(\mathrm{FITO}_{50}\right), 50 \%$ de redução de massa verde da planta $\left(\mathrm{MV}_{50}\right)$ e $50 \%$ de redução de massa seca da planta $\left(\mathrm{MS}_{50}\right)$ em função dos biótipos e cultivares comerciais avaliados - Santa Maria-RS, 2009

\begin{tabular}{|l|c|c|c|}
\hline \multirow{2}{*}{ Biótipo e cltivar } & \multicolumn{3}{|c|}{ Variáveis } \\
\cline { 2 - 4 } & $\mathrm{FITO}_{50}\left(\mathrm{~L} \mathrm{ha}^{-1}\right)$ & $\mathrm{MV}_{50}\left(\mathrm{~L} \mathrm{ha}^{-1}\right)$ & $147,63 \pm 12,97$ \\
\hline IRGA 422 CL & $201,71 \pm 16,62$ & $293,04 \pm 14,39$ & $242,41 \pm 73,37$ \\
\hline Puitá INTA CL & $217,54 \pm 21,43$ & $420,74 \pm 66,36$ & $48,59 \pm 4,75$ \\
\hline IRGA 417 & $70,01 \pm 2,21$ & $50,83 \pm 3,96$ & $129,08 \pm 18,24$ \\
\hline Rio Pardo 1 & $101,02 \pm 17,67$ & $130,65 \pm 28,22$ & $83,41 \pm 7,98$ \\
\hline Pelotas 3 & $25,53 \pm 1,42$ & $52,78 \pm 10,67$ & $56,47 \pm 4,36$ \\
\hline Santa Maria 5 & $30,52 \pm 8,22$ & $53,39 \pm 20,73$ & $66,94 \pm 9,56$ \\
\hline Manoel Viana 2 & $36,89 \pm 0,88$ & $62,32 \pm 7,17$ & $176,91 \pm 25,24$ \\
\hline Catuçaba 1 & $239,25 \pm 27,86$ & $156,01 \pm 36,88$ & $\left.\mathrm{LS}^{-1}\right)$ \\
\hline
\end{tabular}

Tabela 2 - Valores de fator de resistência (FR) para $\mathrm{FITO}_{50}$ e $\mathrm{MS}_{50}$ entre os biótipos Catuçaba 1 e Rio Pardo 1 em relação aos biótipos suscetíveis e cultivares suscetíveis e resistentes - Santa Maria-RS, 2009

\begin{tabular}{|l|c|c|c|c|}
\hline \multirow{2}{*}{$\begin{array}{c}\text { Biótipo de arroz- } \\
\text { vermelhoe cultivar }\end{array}$} & \multicolumn{4}{|c|}{ Fator de Resistência (FR) } \\
\cline { 2 - 5 } & Catuçaba 1 & Rio Pardo 1 & Catuçaba 1 & Rio Pardo 1 \\
\cline { 2 - 5 } & - & 0,4 & - & 0,6 \\
\hline Catuçaba 1 & 2,3 & - & 1,5 & - \\
\hline Rio Pardo 1 & 7,8 & 3,3 & 2,7 & 1,8 \\
\hline Santa Maria 5 & 6,5 & 2,7 & 2,9 & 1,9 \\
\hline Manoel Viana 2 & 9,3 & 3,9 & 2,3 & 1,5 \\
\hline Pelotas 3 & 3,4 & 1,4 & 4,0 & 2,6 \\
\hline IRGA 417 & 1,2 & 0,5 & 1,3 & 0,8 \\
\hline IRGA 422 CL & 1,09 & 0,4 & 0,8 & 0,5 \\
\hline Puitá INTA CL & & & & FITS $_{50}$ \\
\hline
\end{tabular}

${ }^{1 /} \mathrm{FR}=\mathrm{FITO}_{50}$ biótipo resistente/ $\mathrm{FITO}_{50}$ biótipo suscetível ou $\mathrm{FR}=\mathrm{MS}_{50}$ biótipo resistente/ $\mathrm{MS}_{50}$ biótipo suscetível.

acesso Catuçaba 1 demonstrou ser um biótipo que possui o gene de resistência AHAS acetolactato sintase (ALS-resistente), que the permite suportar doses de herbicidas do grupo químico das imidazolinonas, especialmente do imazethapyr, superiores à recomendada para o sistema Clearfield. Essa resistência possivelmente foi adquirida por hibridização com os cultivares Clearfield utilizados em 50\% da área de produção de arroz do Estado, uma vez que esse biótipo foi coletado em área de três anos de cultivo com o cultivar IRGA $422 \mathrm{CL}$.

A análise das sequências parciais do gene ALS (Figura 3) mostrou que o acesso CTÇB1 (Catuçaba 1) coletado na depressão central do Rio Grande do Sul, em área de dois anos de cultivo com o sistema Clearfield, possui o mesmo alelo de resistência que o cultivar IRGA
$422 \mathrm{CL}$, e a proteína predicada apresenta a mutação do aminoácido glutamina para glicina, na posição importante da enzima que confere a resistência ao imazethapyr,

Tudo isso explica o atual quadro encontrado na rizicultura do Rio Grande do Sul e de Santa Catarina, em que o herbicida não tem sido eficiente em controlar determinados biótipos de arroz-vermelho, aumentando ano a ano o percentual de áreas inviabilizadas para a produção do cereal em função da planta daninha (Dornelles et al., 2004; Noldin et al., 2004; Menezes et al., 2008). Dornelles et al. (2004) demonstraram a ocorrência de biótipo de arroz-vermelho resistente a herbicidas imidazolinonas para o Estado do Rio Grande do Sul em estudos realizados com a soja cultivada em várzea em área de rotação arroz/soja. 
O biótipo estudado resistiu a doses três vezes superiores à dose de registro do herbicida Only (imazethapyr $75 \mathrm{~g} \mathrm{~L}^{-1}+$ imazapic $25 \mathrm{~g} \mathrm{~L}^{-1}$ ) registrado no Brasil para o sistema Clearfield. Em áreas de produção de arroz irrigado do Estado de Santa Catarina, Noldin et al. (2004) demonstraram que $22,7 \%$ das plantas de arroz-vermelho da população infestante não foram controladas pela dose recomendada do herbicida Only (imazethapyr $75 \mathrm{~g} \mathrm{~L}^{-1}+$ imazapic $25 \mathrm{~g} \mathrm{~L}^{-1}$ ), enquanto para o Rio Grande do Sul esses pesquisadores encontraram o percentual de $15,5 \%$ de plantas sobreviventes. Nesse trabalho, os autores não concluiram sobre a possibilidade de resistência ou tolerância desses biótipos às imidazolinonas. Recentemente, Menezes et al. (2008) afirmaram que $55,2 \%$ das amostras de arrozvermelho coletadas no Estado do Rio Grande do Sul não foram controladas pelo herbicida Only na dose de registro $\left(1,0 \mathrm{~L} \mathrm{ha}^{-1}\right)$, concluindo que as plantas avaliadas são biótipos com tolerância natural aos herbicidas imidazolinonas.

Kuk et al. (2008) afirmam que nos EUA grande percentual dos biótipos de arrozvermelho é naturalmente tolerante ao herbicida imazethapyr, porém não descartam a possibilidade de evolução de populações de arroz-vermelho resistentes ao herbicida por pressão de seleção pelo uso intensivo do herbicida.
Esses resultados também foram observados no presente trabalho e permitem afirmar que nas áreas de produção de arroz irrigado do Rio Grande do Sul ocorrem simultaneamente biótipos de arroz-vermelho suscetíveis ao herbicida imazethapyr, como o Santa Maria 5, Manoel Viana 2 e Pelotas 3, que se agruparam com o cultivar suscetivel IRGA 417, com biótipos naturalmente tolerantes, como Rio Pardo 1, e com biótipos resistentes, como o Catuçaba 1, que apresenta características fenotípicas e genotípicas muito próximas das dos cultivares Clearfield, inclusive com introgressão do gene de resistência AHAS (ALSresistente), que confere ao arroz-vermelho Catuçaba 1 resistência a doses aplicadas sobre o cultivar Puitá INTA CL (Figura 3).

O cultivar Puitá INTA CL, oriundo da Argentina, foi recentemente registrado no Brasil (AGROFIT, 2008) e está sendo amplamente semeado no Rio Grande do Sul, por tolerar doses do herbicida imazethapyr duas a três vezes superiores às recomendadas para programas de manejo em que se utiliza o cultivar IRGA 422 CL. Nesse contexto, no caso do Rio Grande do Sul, a pressão de seleção parece ser maior que no caso americano, relatado por Kuk et al. (2008). Isso pode estar relacionado ao sistema de cultivo praticado nesse país, onde parte da área produtora de arroz realiza rotação de cultura com soja, utilizando, em anos alternados, outros herbicidas

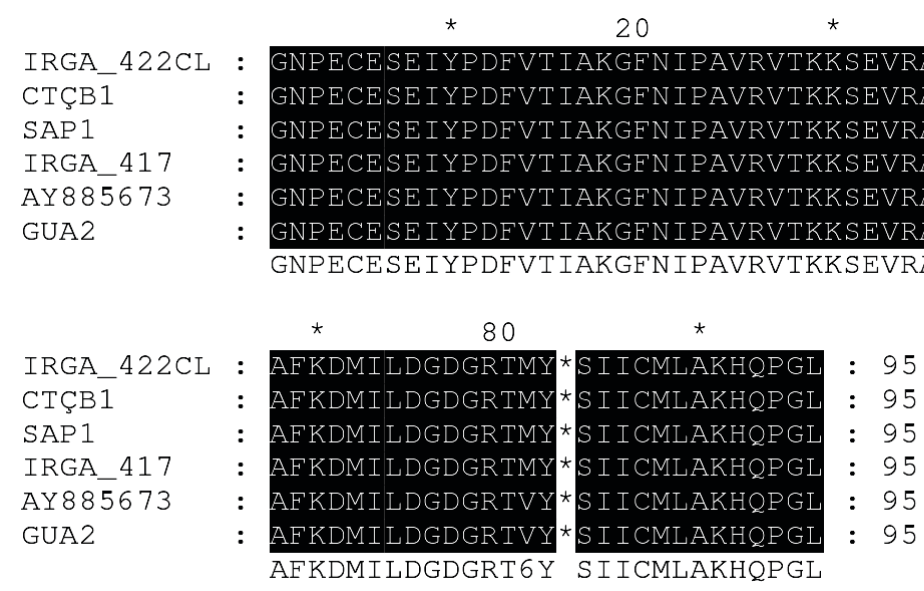

Figura 3 - Alinhamento do gene ALS dos cultivares IRGA 422 CL e IRGA 417 e dos acessos de arroz-vermelho CTÇB1 (Catuçaba 1), GUA2 (Guaíba 2) e SAP1 (Santo Antonio da Patrulha 1); também foi utilizado o acesso AY885673, representando o genoma de Oryza sativa indica. Proteína predita a partir da sequência do gene ALS, onde o aminoácido glutamina é trocado por glicina, sendo este o responsável pela resistência ao herbicida do grupo químico das imidazolinonas, CTÇB (biótipo denominado de Catuçaba 1), Santa Maria-RS, 2009

$40 \quad * \quad 60$

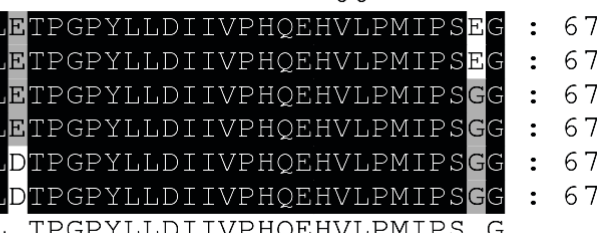

TPGPYLLDIIVPHQEHVLPMIPS G
67 
com mecanismos de ação diferentes dos inibidores de ALS, sobretudo herbicidas como o glifosato, inibidor da enzima EPSPS (5-enolpiruvilchiquimato-3-fosfato sintase) em soja transgênica (Roundup Ready), o que reduz a pressão de seleção imazethapyr-arrozvermelho.

A partir dos resultados apresentados na avaliação de curva de dose-resposta do herbicida imazethapyr sobre biótipos de arrozvermelho e cultivares de arroz irrigado, pode-se inferir que o sistema Clearfield - no atual quadro estabelecido, em que populações de arroz-vermelho resistem a doses superiores às recomendadas para o sistema, inclusive àquelas praticadas para o cultivar Puitá INTA CL - encontra-se ameaçado, uma vez que a adoção de práticas, como o aumento da dose do herbicida utilizado, na tentativa de incrementar o controle da planta daninha, apenas aumenta a pressão de seleção via herbicida para biótipos com grande capacidade de tolerar/resistir a doses superiores às até aqui praticadas, como os biótipos Rio Pardo $1 \mathrm{e}$ Catuçaba 1, o que pode tornar, em curto espaço de tempo, o sistema insustentável.

O biótipo de arroz-vermelho Catuçaba 1 (AHAS-resistente) é resistente ao herbicida imazethapyr em doses duas vezes maiores que as doses comerciais do herbicida, agrupando-se com os cultivares Clearfield (AHAS-resistente), IRGA 422 CL e Puitá INTA CL, em relação a fitointoxicação $\left(\mathrm{FITO}_{50}\right)$, massa verde $\left(\mathrm{MV}_{50}\right)$ e massa seca $\left(\mathrm{MS}_{50}\right)$. Os biótipos Manoel Viana 2, Santa Maria 5 e Pelotas 3 são suscetiveis a doses de imazethapyr inferiores às praticadas no sistema Clearfield - eles agrupam-se com o cultivar suscetivel IRGA 417.

\section{LITERATURA CITADA}

AGOSTINETTO, D. et al. Arroz-vermelho: ecofisiologia e estratégias de manejo. Ci. Rural, v. 31, n. 2, p. 341-349, 2001.

AGROFIT - Sistema de consulta a agrotóxicos registrados no Brasil. Ministério da Agricultura, Pecuária e Abastecimento. Defesa Sanitária Vegetal. Disponível em: <www.agricultura. gov.br/agrofit>. Acessso em: 12 dez. 2008.

AKAGI, H. et al. Microsatellite DNA markers for rice chromosomes. Theor. Applied Genetics, v. 93, n. 7, p. 1071-1077, 1996.
AVILA, L. A. et al. Effect of flood timing on red rice (Oryza spp.) control with imazethapyr applied at different dryseeded rice growth stages. Weed Technol., v. 19, n. 2, p. 476-0480, 2005.

AVILA, L. A. et al. Assessment of acetolactate synthase (ALS) tolerante to imazethapyr in red rice ecotypes (Oryza spp) and imidazolinone tolerant/resistant rice (Oryza sativa) varieties. Pest Manag. Sci., v. 61, n. 2, p. 171-178, 2005.

CHEN, X. et al. Development of a microsatellite framework map providing genome-wide coverage in rice (Oryza sativa L.). Theor. Applied Genetics, v. 95, n. 4, p. 553-567, 1997.

CROUGHAN, T. P. et al. Herbicide-resistant rice offers potential solution to red rice problem. Louisiana Agric., v. 39, n. 3, p. 10-12, 1996.

DORNELLES, S. H. B. et al. Avaliação de acessos de arrozvermelho resistentes a imidazolinonas no Rio Grande do Sul In: CONGRESSO BRASILEIRO DE ARROZ IRRIGADO, 25., 2004, Águas de São Pedro. 2004. Anais... Águas de São Pedro: SBCPD, 2004. CD ROM.

DORNELLES, S.H.B. Caracterização de acessos polimórficos de arroz-vermelhodo Rio Grande do Sul por descritores morfológicos e microssatélites. 2009. 99 f. Tese (Doutorado em Agronomia) - Universidade Federal de Santa Maria, Santa Maria, 2009.

FLECK, N. G. et al. Competitividade relativa entre cultivares de arroz irrigado e biótipo de arroz-vermelho.

Planta Daninha, v. 26, n. 1, p. 101-111, 2008.

FRANS, R.; CROWLEY, H. Experimental design and techniques for measuring and analyzing plant responses to weed control practices. In: SOUTHERN WEED SCIENCE SOCIETY. Research methods in weed science. 3 .ed. Champaign: 1986. p. 29-45.

KUK, Y. I.; BURGOS, N. R.; SHIVRAIN, V. K. Natural tolerance to imazethapyr in red rice (Oryza sativa). Weed Sci., v. 56, p. 1-11, 2008.

MARCHEZAN, E. Arroz vermelho: caracterização, prejuízos e controle. Ci. Rural, v. 24, n. 2, p. 415-421, 1994.

MENEZES, V. G.; MARIOT, C. H. P. Uso desordenado do Clearfield pode comprometer a tecnologia. Lav. Arroz, v. 56, n. 445, p. 21-23, 2008.

MORAES, P. V. et al. Competitividade relativa de soja com arroz-vermelho. Planta Daninha, v. 27, n. 1, p. 35-40, 2009.

MOREIRA, M. S. et al. Resistência de Conyza canadensis e Conyza banariensis ao herbicida glyphosate.

Planta Daninha, v. 25, n. 1, p. 157-164, 2007. 
NOLDIN, J. A. et al. Desempenho de populações híbridas $\mathrm{F}_{2}$ de arroz-vermelho (Oryza sativa) com arroz transgênico resistente ao herbicida amônio-glufosinate. Planta Daninha, v. 22 , n. 3 , p. $181-395,2004$

OLIVEIRA, L. F. V. et al. Isolation of high quality DNA: a protocol combining "rennet" and glass milk. Elect. J.

Biotechnol., v. 12, n. 2, p.1-6, 2009.

RAJGURU, S. N. et al. Mutations in the red rice ALS gene associated with resistance to imazethapyr. Weed Sci., v. 53, n. 5 , p. $567-577,2005$.
SCHWANKE, A. M. L. et al. Caracterização de ecótipos de arroz daninho (Oryza sativa) provenientes de áreas de arroz irrigado. Planta Daninha, v. 26, n. 2, p. 249-260, 2008.

SEEFELDT, S. S.; JENSEN, J. E. E.; FUERST, E. P. Loglogistic analysis of herbicide dose-response relationships. Weed Technol., v. 9, n. 2, p. 218-227, 1995.

TEMNYKH, S. et al. Computational and experimental analysis of microsatellites in rice (Oryza sativa L.): frequency, length variation, transposon associations, and genetic marker potential. Genome Res., v. 11, n. 2, p. 1441-1452, 2001 . 